226

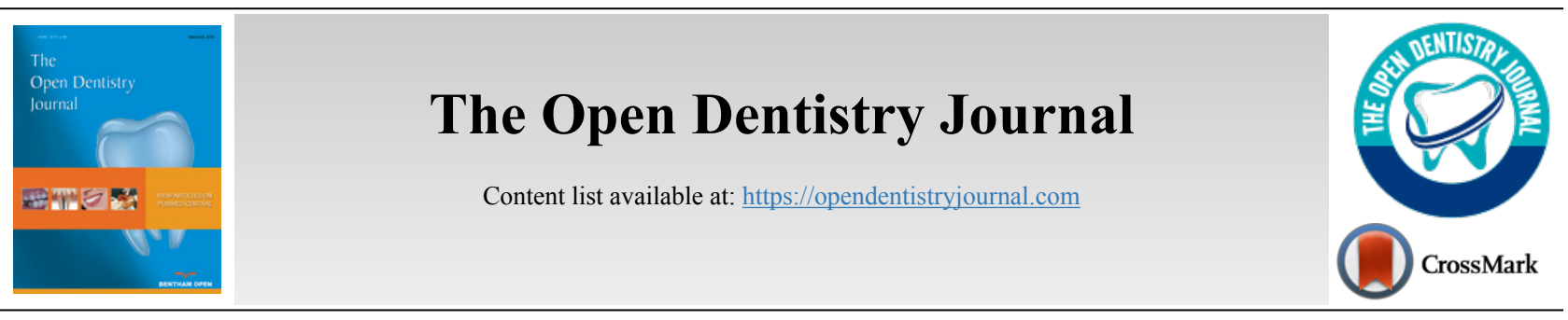

RESEARCH ARTICLE

\title{
Changes of Radiographic Trabecular Bone Density and Peri-Implant Marginal Bone Vertical Dimensions Around Non-Submerged Dental Implants with a Laser-Microtextured Collar after 5 Years of Functional Loading.
}

Renzo Guarnieri ${ }^{1}$, Gabriele Miccoli ${ }^{1}$, Marco Seracchiani ${ }^{1}$, Maurilio D’Angelo ${ }^{1}$, Dario Di Nardo ${ }^{1, *}$ and Luca Testarelli ${ }^{1}$

Department of Oral and Maxillo-Facial Sciences, Sapienza University of Rome, Rome, Italy

\begin{abstract}
:
Objectives:

The progressive peri-implant bone remodeling caused by dynamic cycles of microdamage may change peri-implant bone characteristics and volume after the functional loading.

This prospective study was designed to evaluate the radiographic trabecular bone density and peri-implant vertical dimensional changes around the non submerged dental implant with a laser-microtextured collar (NSLI)s after 5 years of functional loading.

Methods:

Digital periapical radiographs of 58 NSLIs supported fixed single crowns and fixed partial dentures in 26 patients (14 men, mean age of $52 \pm 3.8$ years) were used for comparative evaluation between the implant placement [Baseline (BSL)], the definitive Crowns Delivery (CD) and the 5 years post-functional loading examination (T5). Regions of interest (ROI) were taken into consideration for the measurement of mean gray levels, standard deviation, and variation coefficient. The texture parameters, such as contrast, correlation, angular second moment and entropy, were investigated by using the software ImageJ (v.1.50i), by means of the Gray-level Co-occurrence Matrix (GLCM) Texture Tool plugin. Vertical Periimplant Marginal Bone Level (VPMBL) was assessed at the mesial and the distal sides of each implant by subtracting the measure at BSL from the measure at T5 by means of dedicate software (VixWin Platinum Imaging Software). Mixed regression models were adopted to analyze data. The possible effects of some variables, such as the use of provisional denture, location, crown/implant ratio, type of prosthetic design (single or splinted), on radiographic dimensional vertical changes, gray levels and texture analysis variables were also evaluated.
\end{abstract}

Results:

From BSL to T5, mesial and distal VPMBL showed a statistically significant gain of $0.9 \pm 0.5$, and $0.10 \mathrm{~mm} \pm 0.6$, respectively (P<0.05). From CD to T5, mean gray levels increased from $94.4 \pm 26.8)$ to $111.8 \pm 27.1(\mathrm{P}<0.05)$, while the coefficient of variation decreased from $0.08 \pm 0,03$ to $0.05 \pm 0.04)(\mathrm{P}<0.05)$. Variables showed no statistically significant correlation with texture parameters $(\mathrm{P}>0.05)$.

Conclusion:

NSLIs showed an increase in radiographic vertical peri-implant marginal bone levels and bone density up to 5 years of loading.

Keywords: Bone density, Texture analysis, Dental implants, Laser-microgrooved collar surface, Mixed regression models, Radiographs.

\begin{tabular}{l|l|l|l}
\hline Article History & Received: January 21, 2020 & Revised: April 02, 2020 & Accepted: April 06, 2020
\end{tabular}

\section{INTRODUCTION}

Bone tissue responds positively and negatively to mechanical loads; modifications in terms of the mass of skeletal bone and mineral density are associated with mechanical stimuli and documented in the literature [1 - 3].

* Address correspondence to this author at the Department of Oral and Maxillo Facial Sciences, Sapienza University of Rome, Via Caserta, 6 - 00161 Rome, Italy, Tel: +393393935 527; Email: dario.dinardo@uniroma1.it
Jaws are continuously subject to functional and parafunctional loads while mastication, swallowing, grinding, tapping and clanking: those factors could influence positively or negatively jaws' status [4 - 7]. Peri-implants marginal bone remodeling has been associated with multiple factors, including surgical trauma, implant design, prosthetic considerations and patient habits $[8-10]$. However, some key questions on the influence of each specific factor remain unanswered. Gerhardt et al. suggested that occlusal stimuli may influence peri- 
implant bone remodeling around stable dental implants [11]. Peri-implant bone quantitative and qualitative characteristics could be modified by continuous cycles of microdamage and bone reparation that occur under functional loading [12 - 14]. The implant load can be represented by vertical and horizontal components; improper loads can stress the periapical bone and stresses are usually concentrated at the marginal third of the implant's collar, inducing peri-implant bone remodelling [15]. In cortical bone, dissipation is usually restricted to the implant surrounding area, while in trabecular bone, dissipation occurs at a broader distance [15]. The amount and the quality of the surrounding bone can influence the entity of the load transfer from implants to bone [6]; load transfer can also be influenced by the implant geometry [17, 18].

Attempts to reduce the peak stresses have been made by increasing the area of the peri-implant surface in contact with the bone by modifying the micro and/or macro design of the implant $[19,20]$. Microgrooves ablated on the surface of the implant collar seem to control bone and soft tissue response, as shown in different in vitro and in vivo studies [21]. In dentistry, the term "bone quality" has been often indicated as bone mineral density(BMD) [22 - 24]. Though in orthopedics, BMD-based assessments have been shifted to microstructural investigations of bone architecture, in turn, mineralization and accumulated micro-damage [25], BMD-based diagnosis on radiographic evaluation, is still the gold standard in dentistry. One quantitative method for BMD diagnosis is based on radiographic changes of trabecular bone microstructure evaluated by measurements of the variation of gray levels [22 24]. Gray levels are generally assessed by means of first-order statistics (mean, SD, and coefficient of variation), which describe the occurrence of gray levels without considering the spatial relationship between pixels. Gray levels can be analyzed by using texture parameters like an angular second moment, contrast, entropy and correlation, that measure density, uniformity, sharpness, regularity and intensity [22 24]. Radiographic BMD diagnosis has been used in several studies to evaluate the radiographic changes of trabecular bone density and to quantify peri-implant bone changes under prosthetic loading: according to those studies, bone density changes can be numerically measured by using periapical radiographs $[25,26]$.

This prospective study was aimed to evaluate the radiographic trabecular bone density and peri-implant vertical dimensional changes around non submerged lasermicrotextured implants (NSLI)s after 5 years of functional loading by means of gray levels and texture analysis variables.

The test hypothesis was that there were differences in radiographic changes of peri-implant trabecular bone microstructure after 5 years of loading, against the alternative hypothesis of no differences.

The possible effects of some variables, such as the use of provisional denture, location, crown/implant ratio, type of prosthetic design (single or splinted), on radiographic periimplant bone dimensional vertical changes, gray levels and texture analysis variables were also evaluated.

\section{MATERIALS AND METHODS}

In this prospective study, digital periapical radiographs of 58 NSLIs supported fixed single crowns and fixed partial dentures in consecutively enrolled 26 patients (14 men, mean age of $52 \pm 3.8$ years) were used for a comparative evaluation. All patients signed an informed consent form and the study, approved by the Policlinico Umberto I (Rome, Italy) Ethical Committee (\#4597), was conducted in accordance with the Declaration of Helsinki.

Any partially edentulous patient, being 18 years old or older and able to understand and sign an informed consentf orm was eligible for inclusion in this trial. The edentulous sites should be able to receive one implant of at least $3.8 \mathrm{~mm}$ in diameter and $9 \mathrm{~mm}$ in length, assessed by computed tomography.

Patients were not admitted to the study if any of the following exclusion criteria were present:

- General contraindications to implant surgery;

- Subjected to irradiation in the head and neck area;

- Immunosuppressed or immunocompromised patients;

- Treated or under treatment with intravenous aminobisphosphonates;

- Affected by untreated periodontitis;

- Having poor or alhygiene and motivation; (full-mouth plaque (FMPS) and bleeding score (FMBS) $\geq 25 \%$, recorded at the implant placement)

- Severe intermaxillary discrepancies;

- Smoking more than 10 cigarettes per day;

- Uncontrolled diabetes;

- Pregnant or lactating;

- Substance abusers;

- Psychiatric problems or unrealistic expectations;

- Lack of opposite occluding dentition/prosthesis;

- Acute/chronic infection/inflammation in the area intended for implant placement;

- Patients were participating in other trials, if the present protocol could not be properly followed;

- Extraction sites required bone augmentation or with less than 3 months of healing.

Fifty-eight non-submerged Tissue Level Laser-Lok $(\mathrm{C}$ implants (BioHorizons, Birmingham, AL, USA) were inserted by the same surgeons (RG, LT), using the same one-stage protocol. The implants present a mild rough surface, while the collar is characterized by a $2 \mathrm{~mm}$ smooth, machined top and an underlying $1.3 \mathrm{~mm}$ area with laser textured microgrooves of $8 \mu \mathrm{m}$ (Fig. 1.) 


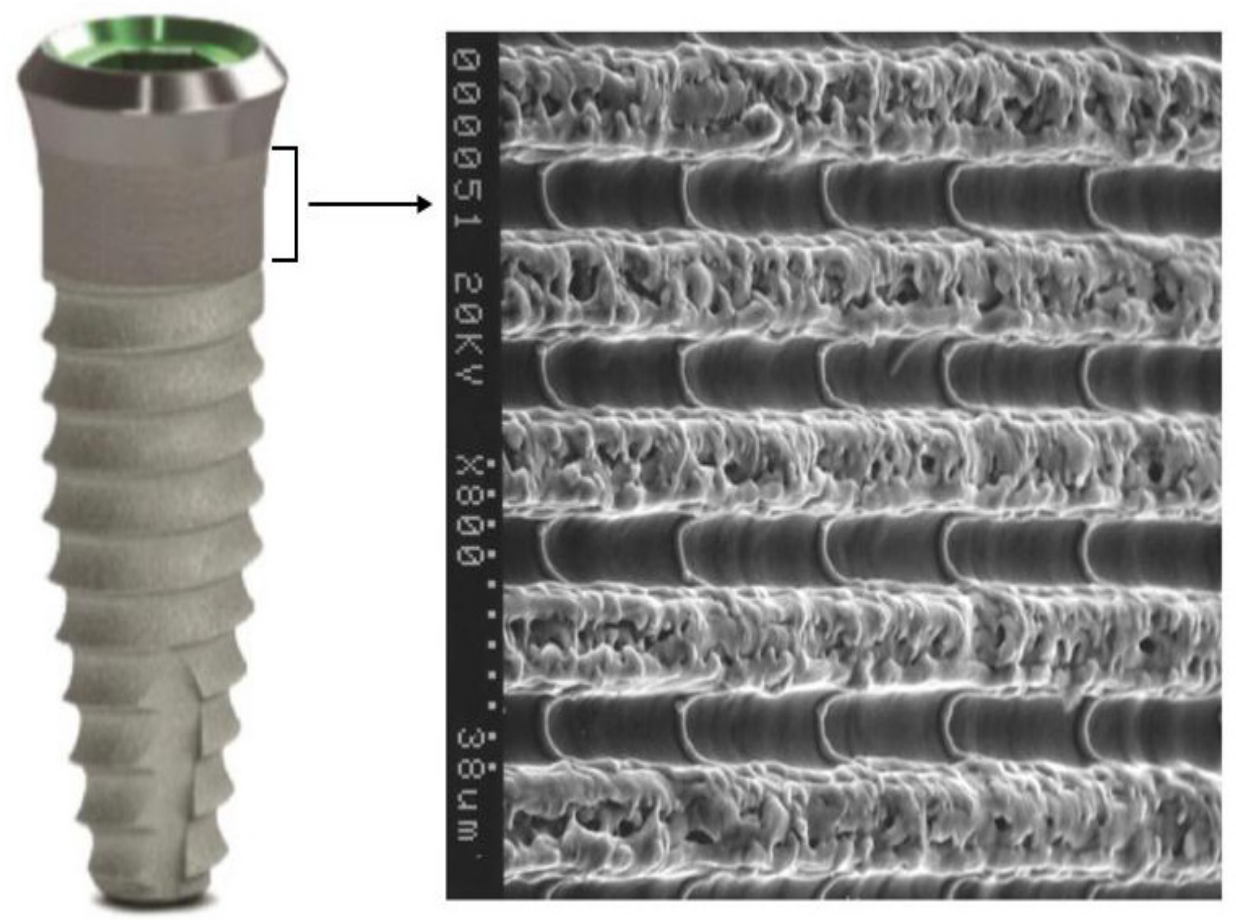

Fig. (1). Tissue level implant (left) and high magnification of laser-microtextured collar surface (right).
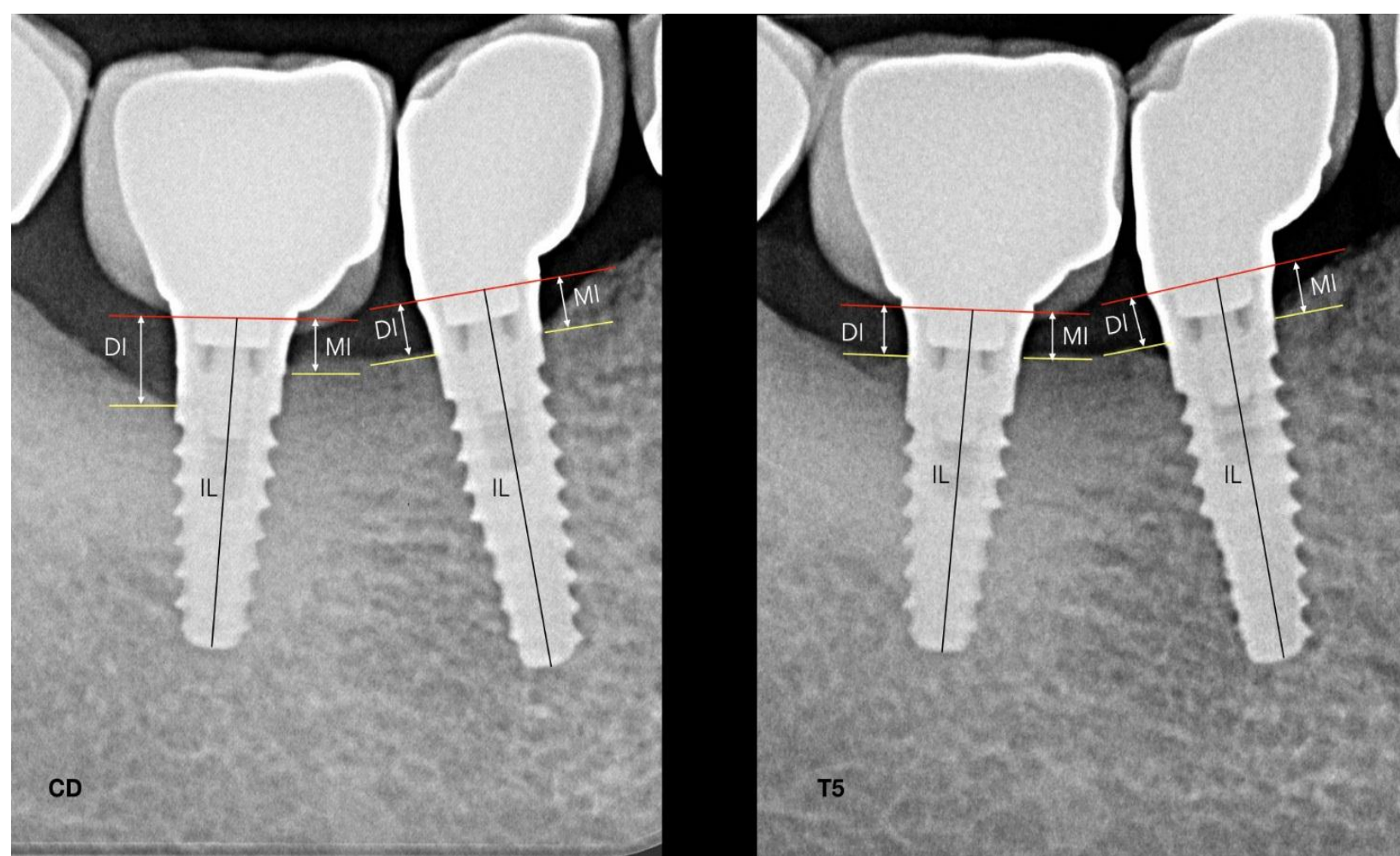

Fig. (2). Radiograph taken at the Crown Delivery (CD) and at the 5-year follow-up (T5).

All fixtures were inserted with the microgrooved border and the smooth surface placed over the bone crest. Radiographs were performed immediately at implant placement [baseline(BSL)], at temporary or definitive crowns delivery
(CD)4/6 months after surgery, and at each year after loading (T1, T2, T3, T4, and T5), with a paralleling technique using a Rinn film holder. A customized silicone holder was arranged for each patient due to correctly reproducing the same position 
for every radiograph.

High resolution radiographs were taken by using phosphor films (Vista Scan, Durr Dental, Bietigheim-Bissingen, Germania) with a dental x-ray tube (TM 2002 Planmeca Proline CC, Planmeca Group Helsinki, Finland) equipped with a long tube that operated at $70 \mathrm{Kw} / 7.5 \mathrm{~mA}$., total aluminum filtration of $3.22 \mathrm{~mm}$, and focus distance of $40 \mathrm{~cm}$. The exposure times were 0.65 seconds for maxilla and 0.55 seconds for the mandible. Specialized software (DBSWIN software, Durr Dental Italy S.r.l) was used for linear measurements of vertical peri-implant marginal bone levels (VPMBL).

The radiographic implant length (IL) and the mesial and distal vertical residual bone height were measured in $\mathrm{mm}$. The coefficient derived from the ratio: real length of the implant/IL was adopted to avoid false measurements due to radiographic distortions. Taking as reference the collar of the implant, radiographicVPMBLwas assessed at the mesial and the distal sides by subtracting marginal bone levels at BSL from marginal bone levels at T5 Fig. (2). Radiographically, the crown-to-implant ratio (C/I ratio) length was based on the supporting bone. The crown length was considered as the average of the mesial and distal distances, from the occlusal/ incisal to the bone-implant contact at the crestal bone. The length of the implant was considered as the mean of the distal and mesial distances from the bone crest to the apical portion of the implant. According to the $\mathrm{C} / \mathrm{I}$ ratios, implants were divided into two groups: $\mathrm{A} \mathrm{C} / \mathrm{I}$ ratio $\leq 1$ and $>1$.

For the gray levels and texture analysis, radiographs taken at $\mathrm{CD}$ and at T5 were used. The radiographic images were standardized at 8-bit with pixels in the range from 0 (black) to 255 (white). The free software ImageJ (v.1.50i, National Institutes of Health) was used to collect data on both gray levels and texture analysis by means of the GLCM Texture Tool plugin. The examinator (RG) drew two regions of interests (ROIs) of $20 \AA \sim 20$ pixels at the mesial and distal sides of each implant, in a $200 \AA \sim$ magnification for better identification of the pixels, close to the border of the gritblasted surface flushing with the bone crest, and under the 2 $\mathrm{mm}$ of laser-microgrooved surface placed over the bone crest, considering the first bone/implant contact. One additional ROI was drawn on the body of the implant in the shoulder as reference. It represented an approximately constant density that can be used to normalize the average intensity measurements from the rest of ROIs and related them to the bone density. The pixel size of all radiographs resulted in an ROI area of 1.28 $\mathrm{mm}^{2}$ (Figs. 3 and 4). The bone density calculations were performed by first obtaining the grey shades of the ROI and then dividing them by the grey shades defined by a reference ROI. The following image data were collected: (a) first-order statistics: mean gray levels, SD, and coefficient of variation; and (b) second-order statistics or texture analysis: angular second moment, contrast, entropy, and correlation.

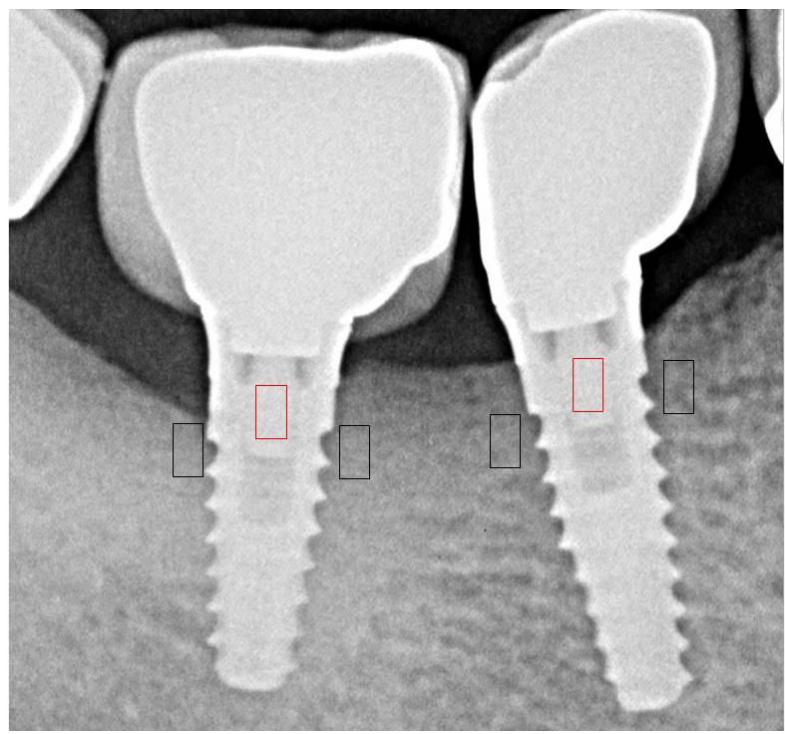

Fig. (3). Regions of interest(ROI) were selected on radiographs taken immediately after prosthesis delivery.

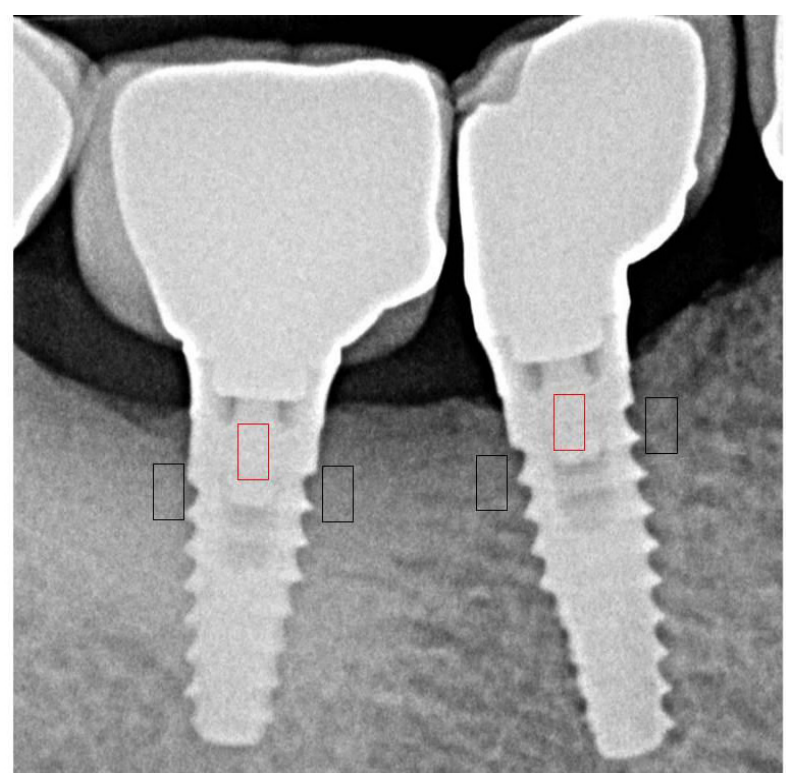

Fig. (4). Regions of interest were selected on radiographs taken 5 years after loading.

In addition, the maximum occlusal force was recorded using a cross-arch compressive force transducer while the patient was seated in an upright position with no head support. For 28 of 58 implants, temporary heat cured acrylic resin crowns (Meliodent Bayer Dental Germany) were made.

\subsection{Statistical Analysis}

Data of linear measurements of VPMBL were analyzed by means of Mann-Whitney test. A P value $<0.05$ was considered significant. A linear regression of the mixed effects model for correlated data (for more than one implant installed in one patient) was used to analyze the relationship between the changes in gray levels (mean gray levels, SD, and coefficient of variation), texture parameters (angular second moment, 
contrast, entropy, and correlation) and the effect of factors over time. This multilevel model with random effects estimates the variation in the baseline data over time, considering the correlation between measures. The models were adjusted separately for each parameter and also tested the interaction between time and factors. The significance level was set at 0.05 .

\section{RESULTS}

In Table 1, the descriptive analysis of the sample is reported. In Table 2, mean values of linear measurements of VPMBL at BSL and T5 are reported. Compared to BSL, at T5, the mesial and distal VPMBL showed a statistically significant gain of $0.09 \pm 0.5$ and $0.10 \pm 0.6 \mathrm{~mm}$, respectively $(\mathrm{P}<0.05)$ (Fig. 4).

In Table 3, mean values of gray levels, and texture parameters at $\mathrm{CD}$ and at $\mathrm{T} 5$ are reported. From $\mathrm{CD}$ to $\mathrm{T} 5$, mean gray levels increased from $94.4 \pm 26.8$ to $111.8 \pm 27.1(\mathrm{P}<0.05)$, while the coefficient of variation decreased from $0.08 \pm 0,03$ to $0.05 \pm 0.04(\mathrm{P}<0.05)$. Table 4 describes the results of the mixed regression models. The time of loading was statistically correlated with the mean of gray level $(\mathrm{P}<0.05)$. No statistically significant correlation between variables (use of provisional denture, location, crown/implant ratio, single or splinted crowns) and gray levels and texture parameters were found $(\mathrm{P}>0.05)$.

Table 1. Descriptive analysis of the sample.

\begin{tabular}{|c|c|c|r|}
\hline Variable & Frequency & Mean & SD \\
\hline Patients: & 26 & 52 & 3.8 \\
Sex: male & 14 & & \\
Age: years & & & \\
\hline Implants: & 58 & & \\
Maxilla & 24 & & \\
Mandible & 34 & & \\
Single & 28 & & \\
Splinted & 30 & & \\
\hline Provisional crows & 28 & & \\
\hline Maximum bite force & 31 & 470 & 132 \\
\hline
\end{tabular}

Table 2. Linear measurements of vertical peri-implant marginal bone level (VPMBL) in $\mathrm{mm}$.

\begin{tabular}{|l|l|l|l|l|l|l|}
\hline Parameters & BSL & T1 & T2 & T3 & T4 & T5 \\
\hline VPMBL mesial & 3.33 & 3.30 & 3.27 & 3.25 & 3.23 & 3.22 \\
$($ SD $)$ & $(0.6)$ & $(0.5)$ & $(0.3)$ & $(0.3)$ & $(0.4)$ & $(0.5) *$ \\
\hline VPMBL distal & 3.31 & 3.29 & 3.25 & 3.22 & 3.21 & 3.21 \\
$($ SD) & $(0.3)$ & $(0.4)$ & $(0.3)$ & $(0.4)$ & $(0.5)$ & $(0.6) *$ \\
\hline
\end{tabular}

$\mathrm{BSL}=$ at the implant placement; $\mathrm{T} 1, \mathrm{~T} 2, \mathrm{~T} 3, \mathrm{~T} 4$, and $\mathrm{T} 5=$ at the 1, 2, 3, 4 and 5year evaluation, ${ }^{*} P<0.05$.

Table 3. Variation in first- and second-order parameters [mean values and (SD)].

\begin{tabular}{|l|l|l|l|l|l|l|}
\hline Parameters & CD & T1 & T2 & T3 & T4 \\
\hline Mean Gray levels* & $94.4(26,8)$ & $96.7(22.1)$ & $99.4(21.9)$ & $103.2(25.5)$ & $109.7(28.3)$ \\
\hline SD & $6.98(2.83)$ & $6.59(2.17)$ & $6.43(2.09)$ & $6.37(2.91)$ & $6.23(3.11)$ \\
\hline Coefficient of variation* & $0.08(0.03)$ & $0.06(0.02)$ & $0.06(0.02)$ & $0.05(0.03)$ & $0.04(0.02)$ \\
\hline Angular second moment & $0.03(0.01)$ & $0.03(0.01)$ & $0.03(0.01)$ & $0.03(0.01)$ & $0.03(0.01)$ \\
\hline Contrast & $6.27(2.94)$ & $6.29(2.57)$ & $6.13(2.67)$ & $6.07(2.91)$ & $5.93(3.11)$ & $0.05(0.04)$ \\
\hline Entropy & $4.39(0.25)$ & $4.32(0.22)$ & $4.35(0.21)$ & $4.37(0.28)$ & $4.30(0.29)$ \\
\hline Correlation & $0.03(0.02)$ & $0.03(0.02)$ & $0.03(0.02)$ & $0.03(0.02)$ & $0.03(0.02)$ \\
\hline
\end{tabular}

$\mathrm{CD}=$ at crowns delivery; $\mathrm{T} 1, \mathrm{~T} 2, \mathrm{~T} 3, \mathrm{~T} 4$, and $\mathrm{T} 5=$ at the $1,2,3,4$ and 5 -year evaluation, $* P<0.05$.

Table 4. Variation in first- and second-order parameters as a function of time, provisional, $\mathrm{C} / \mathrm{I}$ ratio, prosthetic design and $\operatorname{arch}[$ mean and (SD)].

\begin{tabular}{|c|c|c|c|c|c|c|c|c|c|c|}
\hline \multirow[t]{2}{*}{ Factor } & \multicolumn{2}{|r|}{ Time } & \multicolumn{2}{|c|}{ Provisional } & \multicolumn{2}{|c|}{$\mathrm{C} / \mathrm{I}$ ratio } & \multicolumn{2}{|c|}{ Prosthetic Design } & \multicolumn{2}{|l|}{ Arch } \\
\hline & T3 & T5 & Yes & No & $<1$ & $\geq 1$ & Single & Splinted & Sup. & Inf. \\
\hline Mean grey level & $\begin{array}{l}4.136 * \\
(2.869)\end{array}$ & $\begin{array}{l}9.587 * \\
(4.677)\end{array}$ & $\begin{array}{l}9.398 \\
(3.762)\end{array}$ & $\begin{array}{l}9.775 \\
(4.032)\end{array}$ & $\begin{array}{l}9.542 \\
(4.429)\end{array}$ & $\begin{array}{l}9.531 \\
(3.791) \\
\end{array}$ & $\begin{array}{l}9.377 \\
(4.429) \\
\end{array}$ & $\begin{array}{l}9.796 \\
(3.791)\end{array}$ & $\begin{array}{c}9.945 \\
(3.203) \\
\end{array}$ & $\begin{array}{c}9228 \\
(2.982) \\
\end{array}$ \\
\hline SD & $\begin{array}{l}-0.364 \\
(0.113)\end{array}$ & $\begin{array}{l}-0.516 \\
(0.473)\end{array}$ & $\begin{array}{l}0.563 \\
(0.031)\end{array}$ & $\begin{array}{l}0.468 \\
(0.028)\end{array}$ & $\begin{array}{c}0.542 \\
(0.045)\end{array}$ & $\begin{array}{c}0.587 \\
(0.099)\end{array}$ & $\begin{array}{c}0.492 \\
(0.061)\end{array}$ & $\begin{array}{c}0.528 \\
(0.052)\end{array}$ & $\begin{array}{l}0.511 \\
(0.03)\end{array}$ & \begin{tabular}{|c|}
0.523 \\
$(0.034)$ \\
\end{tabular} \\
\hline Coefficient of variation & $\begin{array}{l}-0.003 * \\
(0.001)\end{array}$ & $\begin{array}{l}-0.013 * \\
(0.006)\end{array}$ & $\begin{array}{l}-0.011 \\
(0.004)\end{array}$ & $\begin{array}{l}-0.015 \\
(0.005)\end{array}$ & $\begin{array}{l}-0.012 \\
(0.003)\end{array}$ & $\begin{array}{l}-0.014 \\
(0.005)\end{array}$ & $\begin{array}{c}-0.013 \\
(0.004)\end{array}$ & $\begin{array}{c}-0.016 \\
(0.008)\end{array}$ & $\begin{array}{l}-0.012 \\
(0.007)\end{array}$ & \begin{tabular}{|l|}
-0.015 \\
$(0.003)$
\end{tabular} \\
\hline Contrast & $\begin{array}{l}-0.648 \\
(0.826) \\
\end{array}$ & $\begin{array}{l}-0.486 \\
(0.933)\end{array}$ & $\begin{array}{l}-0.516 \\
(1.648)\end{array}$ & $\begin{array}{l}-0.457 \\
(1.701) \\
\end{array}$ & $\begin{array}{l}-0.412 \\
(1.433) \\
\end{array}$ & $\begin{array}{l}-0.554 \\
(1.385) \\
\end{array}$ & \begin{tabular}{|c|}
-0.508 \\
$(1.136)$ \\
\end{tabular} & $\begin{array}{c}-0.465 \\
(1.288)\end{array}$ & $\begin{array}{c}-0.461 \\
(1.245) \\
\end{array}$ & \begin{tabular}{|c|}
-0.509 \\
$(1.354)$ \\
\end{tabular} \\
\hline Entropy & $\begin{array}{l}-0.026 \\
(0.075)\end{array}$ & $-0.046(0.001)$ & $\begin{array}{l}-0.051 \\
(0.209)\end{array}$ & $\begin{array}{l}-0.042 \\
(0.312) \\
\end{array}$ & $\begin{array}{l}-0.049 \\
(0.182) \\
\end{array}$ & $\begin{array}{l}-0.042 \\
(0.201) \\
\end{array}$ & $\begin{array}{c}-0.052 \\
(0.202) \\
\end{array}$ & $\begin{array}{c}-0.041 \\
(0.199)\end{array}$ & $\begin{array}{l}-0.050 \\
(0.202)\end{array}$ & \begin{tabular}{|c|}
-0.043 \\
$(0.199)$ \\
\end{tabular} \\
\hline Angular second moment & $\begin{array}{c}0.001 \\
(0.001)\end{array}$ & $\begin{array}{l}0.001 \\
(0.001)\end{array}$ & $\begin{array}{c}0.001 \\
(0.003)\end{array}$ & $\begin{array}{c}0.002 \\
(0.002)\end{array}$ & $\begin{array}{c}0.001 \\
(0.001)\end{array}$ & $\begin{array}{c}0.001 \\
(0.001)\end{array}$ & $\begin{array}{c}0.001 \\
(0.001)\end{array}$ & $\begin{array}{c}0.001 \\
(0.001)\end{array}$ & $\begin{array}{c}0.001 \\
(0.001)\end{array}$ & \begin{tabular}{|c|}
0.001 \\
$(0.001)$
\end{tabular} \\
\hline Correlation & $\begin{array}{c}0.002 \\
(0.005)\end{array}$ & $\begin{array}{l}0.002 \\
(0.007)\end{array}$ & $\begin{array}{c}0.001 \\
(0.011)\end{array}$ & $\begin{array}{c}0.002 \\
(0.012)\end{array}$ & $\begin{array}{c}0.001 \\
(0.006)\end{array}$ & $\begin{array}{c}0.002 \\
(0.005)\end{array}$ & $\begin{array}{c}0.002 \\
(0.004)\end{array}$ & $\begin{array}{c}0.002 \\
(0.006)\end{array}$ & $\begin{array}{c}0.002 \\
(0.004)\end{array}$ & \begin{tabular}{|c|}
0.002 \\
$(0.006)$
\end{tabular} \\
\hline
\end{tabular}




\section{DISCUSSION}

This prospective study showed an increase of radiographic trabecular bone density, by means of gray levels and texture analysisvariables, around dental implant sunder function up to 5 years. Although in orthopedics, bone quality is assessed by structural evaluations and not only by bone mineral density, in implant dentistry, those evaluations are still challenging since devices capable of accurately evaluating bone structure have yet to be developed. One quantitative method to analyze the bone density in periapical radiographs is represented by the measurements of the variation of gray levels variation and texture parameters [23 - 25]. Gray levels and texture parameters assessed in periapical images showed an association with peak insertion torque, resonance frequency analysis measurements, and with the histologic bone-toimplant contact (BIC) [23 - 25]. In the case of radiographic images, the gray tone is correlated with the density of bone: higher the mean value of gray levels, denser is the bone. The coefficient of variation (SD and mean gray value ratio), is correlated with the uniformity of the radiographic representation: the lower the coefficient of variation, the less variation among the gray levels is present [12]. According to the jawbone classification suggested by Lekholm and Zarb, since bone type 1 is mainly cortical, it results in more radiopaque with an arrow greyscale (entropy) and pixel values which minimally differ from the mean (standard deviation). This type of bone results in small values of the ratio between standard deviation and the mean levels of gray (coefficient of variation). Bone types 2, 3 and 4, show a gradual increase in the greyscale due to the radiographic radiolucency given by the predominance of more representative medullar spaces [25]. Therefore, these bone types will show a gradually lower mean grey level and a larger variation of their pixels values, thereby determining a higher coefficient of variation from bone types 2 to 4 . In this prospective study, measurements carried out at CD and at T5, showed around the investigated implants an increase of mean gray levels, associated with a decrease in the coefficient of variation, which indicate an increase in bone trabeculae $[23,25]$. Moreover, results from texture analysis showed a trend for bone density increase overtime. Experimental animal studies indicated that bone remodeling around implants can be stimulated by appropriately control loading forces: this can contribute to maintain implant stability [27]. Evidence of bone remodeling with the presence of osteoclasts were revealed around implants under functional loading; it has also been evidenced a higher degree of contact between bone and implant $[28,29]$. Mechanical loading also increases bone volume fraction, the trabecular thickness and content, and alters trabecular morphology [30,31]. The results of the present study are in agreement with data published by Carneiro et al. [32] and Gerhardtet al. [11]who found a significant decrease in grey levels after 1 and 3 years of conventional implant loading. Different results have been reported by Mundim et al. [33] and Appleton et al. [34]who showed no statistical difference in bone density at subcrestal level after implant loading. Mathematical methods used to analyze the bone density and to quantify trabecular bony structure in periapical radiographs are not sensitive to small alignment variations or over- or sub-exposure, while are sensitive to the size of ROIs and ROI placement [35 - 37].This could justify the different results reported by other studies. Since it is known that most stress transmitted to the periimplant bone is concentrated in the upper region of the implant body in contact with bone [15], in the present study ROIs were carefully vertically positioned between the border of the gritblasted surface flushing with the bone crest (under the $2 \mathrm{~mm}$ of laser-microgrooved surface placed over the bone crest), and the first implant thread level. MBL may result from the density of bone, implant design, surgical trauma at implant insertion, occlusal overload, smoking habit and periodontal status [8 10]. However, the precise mechanisms of this phenomenon are not yet completely known. Advances in bone cell biology demonstrated that bone resorption is regulated by the interplay of a cytokine system belonging to tumor necrosis factor ligand and receptor superfamilies, which comprise the osteoclastogenesis system, the receptor activator nuclear factor kappa-B (RANK)/RANK ligand (RANKL)/osteoprotegerin (OPG) [38]. RANKL and OPG regulate bone resorption by positive or negative stimulation of RANK on osteoclast cells. The positive association of genetic markers for RANK and OPG has been observed in bone-destructive diseases, such as Paget's disease, familial expansile osteolysis and osteoporosis $[39,40]$. In addition, studies have shown that the relative ratio of RANKL/OPG is higher in sites with periodontitis when compared to healthy sites [41]. In each patient of the present study, the same general and local health conditions and the same surgical and prosthetic conditions were present. Moreover, the surface treatment and the implant-abutment interface characteristics are similar for all the implants. Therefore, the external loading stress was the major factor influencing radiographic parameter changes. The effect of loading time as a significant factor for peri-implant bone densification, evaluated by a mean of gray levels and texture analysis variables,was also reported by Gerhardt et al. [11] and Appleton et al. [34], who founded an increase in radiographic bone density at 3- and 1-year, respectively. Regarding the different loading protocols, Aköglan et al. [41]observed a significant increase in bone density at the cervical region for immediate, early, and delayed loading implants, while Ghoveizi et al. [42] reported an increase in bone density around progressively loaded compared to conventional loaded implants. In the current study, the use of provisional denture showed no statistically significant correlation with gray levels and texture parameters. However, no progressive loading protocol was used for the temporary resin crowns. Regarding the effect of other examined variables, no statistically significant correlation between location, crown/implant ratio, type of prosthetic design (single or splinted) and gray levels and texture parameters was found. These results differ from what reported by Appleton et al. [34], and Aköglan et al. [41]. However, these authors used different methods [digital subtraction radiography/ implant stability values (ISQ)] to quantify changes, and shorter follow-up. One interesting data emerged from the current study is related to vertical periimplant marginal bone changes between the BSL and the 5year examination. Peri-implant marginal bone loss is a phenomenon commonly described around dental implants. It was accepted that $1 \mathrm{~mm}$ of MBL could be expected in the first year after implant placement and then $0.2 \mathrm{~mm}$ of MBL on 
average might occur after that [43]. After 5 years of loading, the mean vertical radiographic mesial and distal peri-implant marginal bone levels recorded around the investigated NSLIs showed a statistically significant gain of $0.09 \mathrm{~mm}$ (SD 0.5), and $1.0 \mathrm{~mm}$ (SD 0.6), respectively $(\mathrm{P}<0.05)$. A possible explanation of the results of the current study could be linked with the ability of the laser-microtextured collar surface to create a soft tissue seal that counteracts the downgrowth of epithelium, and protects the underline bone from the ora lenvironment [44, 45]. Epithelial downgrowth on titanium surfaces is attributable to coronal-apical proliferation and migration of epithelial cells derived from the mucosa surrounding the wound surface, forming a junctional epithelium. The presence of granulation tissue in contact with the transmucosal titanium surfaces is thought to be one of factors favoring apical epithelial migration, and the related MBL [46]. Material properties appear to be a factor affecting epithelial downgrowth. Kim et al. [47] compared the effects of abutment shapes relative to MBL. They compared implants with micro-textured transmucosal profiles, machined profiles, and straight anodically oxidized profiles. Aroundmachined and anodically oxidized profiles, the junctional epithelium was found longer, around laser-microtextured profiles epithelium was shorter, connective tissue attachment was more extended and the bone-level stable. A recent gene profiling analysis [48]documented that the mucosal wound healing around dental implants is influenced by the topographic nature of the coronal surface. In biopsies obtained after 2, 4, and 8 weeks, at the laser-microtextured vs. machined implant collar surface, a differential gene expression was revealed. Laser-modified surfaces can upregulate mRNAs encoding keratins and proteins that can protect the cornified epithelium. Moreover, after 4 weeks, it was observed the upregulation of mRNAs encoding proteins associated with the formation of collagen fibrils. Based on these data, one might speculate that repetitive nanosize surface features created with a laser on the implant collar have the ability to influence the soft tissue healing around dental implants. In natural teeth, collagen bundles are inserted into the root cementum and this deters the downgrowth migration of the epithelium: epithelial downgrowth around implants could be avoided by the aid of a firm physical attachment between the soft connective tissue and the implant collar.

Limitations of the present study are connected with the sole use of periapical radiographs which allow bone tissue visualization only in mesial and distal implant sides. Since the buccal and cortical plates of the mandible and maxilla do not cast a discernible image on periapical radiographs, and trabecular bone is a substantive contributor to the bone striae seen on periapical radiographs, it would be interesting to evaluate the bone density in tridimensional exams such as computed tomography, obtaining circumferential information of the process around the implants but, in terms of radioprotection, it is still more invasive than periapical radiographs. Therefore, studies similar to these, often represent the first line of clinical evidence, which underscores its clinical value.

\section{CONCLUSION}

Non-submerged laser-microgrooved implants showed an increase in radiographic peri-implant marginal bone levels and bone density. In conclusion, an increase in mean gray levels and a decrease in coefficient of variation have been assessed up to 5 years of loading.

\section{ETHICS APPROVAL AND CONSENT TO PARTICIPATE}

Ethical approval was given by the Ethical Committee of Policlinico Umberto I of Rome, Italy, date 08/06/2017, Rif.CE 4597, Prot. n. 528/17.

\section{HUMAN AND ANIMAL RIGHTS}

No animals were used in this research. All human research procedures followed were in accordance with the ethical standards of the committee responsible for human experimentation (institutional and national), and with the Helsinki Declaration of 1975, as revised in 2013.

\section{CONSENT FOR PUBLICATION}

Written informed consent was obtained prior to the study.

\section{AVAILABILITY OF DATA AND MATERIALS}

The data that support the findings of this study are available from the corresponding author, [D. D. N], upon reasonable request.

\section{FUNDING}

None.

\section{CONFLICT OF INTEREST}

The authors declare that there is no conflict of interest regarding the publication of this article.

\section{ACKNOWLEDGEMENTS}

Declared none.

\section{REFERENCES}

[1] Krahl H, Michaelis U, Pieper HG, Quack G, Montag M. Stimulation of bone growth through sports. A radiologic investigation of the upper extremities in professional tennis players. Am J Sports Med 1994; 22(6): 751-7.

[http://dx.doi.org/10.1177/036354659402200605] [PMID: 7856798]

[2] Chilibeck PD, Sale DG, Webber CE. Exercise and bone mineral density. Sports Med 1995; 19(2): 103-22.

[http://dx.doi.org/10.2165/00007256-199519020-00003] [PMID: 7747001]

[3] Smith SM, Heer M, Shackelford LC, et al. Bone metabolism and renal stone risk during International Space Station missions. Bone 2015; 81 : 712-20.

[http://dx.doi.org/10.1016/j.bone.2015.10.002] [PMID: 26456109]

[4] Cortes AR, Jin Z, Morrison MD, Arita ES, Song J, Tamimi F. Mandibular tori are associated with mechanical stress and mandibular shape. J Oral Maxillofac Surg 2014; 72(11): 2115-25.

[http://dx.doi.org/10.1016/j.joms.2014.05.024] [PMID: 25239215]

[5] Morrison MD, Tamimi F. Oral tori are associated with local mechanical and systemic factors: a case-control study. J Oral Maxillofac Surg 2013; 71(1): 14-22.

[http://dx.doi.org/10.1016/j.joms.2012.08.005] [PMID: 23010373]

[6] Wise GE, King GJ. Mechanisms of tooth eruption and orthodontic tooth movement. J Dent Res 2008; 87(5): 414-34. 
[http://dx.doi.org/10.1177/154405910808700509] [PMID: 18434571]

[7] Davies SJ, Gray RJ, Linden GJ, James JA. Occlusal considerations in periodontics. Br Dent J 2001; 191(11): 597-604.

[http://dx.doi.org/10.1038/sj.bdj.4801245] [PMID: 11770945]

[8] Galindo-Moreno P, León-Cano A, Ortega-Oller I, Monje A. O'Valle F, Catena A. Marginal bone lossas success criterion in implantdentistry: beyond $2 \mathrm{~mm}$. Clin. OralImpl. Res 2015; 26: e28-34. [PMID: 24383987]

[9] Isola G, Polizzi A, Alibrandi A, Indelicato F, Ferlito S. Analysis of Endothelin-1 Concentrations in Individuals with Periodontitis. Sci Rep 2020; 10(1): 1652 .

[http://dx.doi.org/10.1038/s41598-020-58585-4] [PMID: 32015361]

[10] Isola G, Polizzi A, Muraglie S, Leonardi R, Lo Giudice A. Assessment of Vitamin C and Antioxidant Profiles in Saliva and Serum in Patients with Periodontitis and Ischemic Heart Disease. Nutrients 2019; 11(12)E2956

[http://dx.doi.org/10.3390/nu11122956] [PMID: 31817129]

[11] Gerhardt MN, Villarinho EA, Rockenbach MIB, Vigo Á, Dos Reis RCP, Shinkai RSA. Radiographic changes of trabecular bone density after loading of implant-supported complete dentures: A 3-year prospective study. Clin Implant Dent Relat Res 2019; 21(5): 1041-7. [http://dx.doi.org/10.1111/cid.12829] [PMID: 31373178]

[12] Kuroshima S, Kaku M, Ishimoto T, Sasaki M, Nakano T, Sawase T. A paradigm shift for bone quality in dentistry: A literature review. J Prosthodont Res 2017; 61(4): 353-62

[http://dx.doi.org/10.1016/j.jpor.2017.05.006] [PMID: 28633987]

[13] Simons WF, De Smit M, Duyck J, Coucke W, Quirynen M. The proportion of cancellous bone as predictive factor for early marginal bone loss around implants in the posterior part of the mandible. Clin Oral Implants Res 2015; 26(9): 1051-9.

[http://dx.doi.org/10.1111/clr.12398] [PMID: 24750281]

[14] Albrektsson T, Chrcanovic B, Östman PO, Sennerby L. Initial and long-term crestal bone responses to modern dental implants. Periodontol 2000 2017; 73(1): 41-50.

[http://dx.doi.org/10.1111/prd.12176] [PMID: 28000272]

[15] Hansson S. A conical implant-abutment interface at the level of the marginal bone improves the distribution of stresses in the supporting bone. An axisymmetric finite element analysis. Clin Oral Implants Res 2003; 14(3): 286-93.

[http://dx.doi.org/10.1034/j.1600-0501.2003.140306.x]

[PMID: 12830797]

[16] Clift SE, Fisher J, Watson CJ. Finite element stress and strain analysis of the bone surrounding a dental implant: effect of variations in bone modulus. Proc Inst Mech Eng H 1992; 206(4): 233-41.

[http://dx.doi.org/10.1243/PIME_PROC_1992_206_295_02] [PMID: 1300115]

[17] Herekar MG, Patil VN, Mulani SS, Sethi M, Padhye O. The influence of thread geometry on biomechanical load transfer to bone: A finite element analysis comparing two implant thread designs. Dent Res J (Isfahan) 2014; 11(4): 489-94. [PMID: 25225563]

[18] Pérez MA, Prados-Frutos JC, Bea JA, Doblaré M. Stress transfer properties of different commercial dental implants: a finite element study. Comput Methods Biomech Biomed Engin 2012; 15(3): 263-73. [http://dx.doi.org/10.1080/10255842.2010.527834] [PMID: 21170768]

[19] Lollobrigida M, Maritato M, Bozzuto G, Formisano G, Molinari A, De Biase A. Biomimetic Implant Surface Functionalization with Liquid LPRF Products: In Vitro Study. BioMed Res Int 2018; 20189031435 [http://dx.doi.org/10.1155/2018/9031435] [PMID: 29854805]

[20] Lollobrigida M, Lamazza L, Capuano C, et al. Physical Profile and Impact of a Calcium-Incorporated Implant Surface on Preosteoblastic Cell Morphologic and Differentiation Parameters: A Comparative Analysis. Int J Oral Maxillofac Implants 2016; 31(1): 223-31.

[http://dx.doi.org/10.11607/jomi.4247] [PMID: 26800182]

[21] Ketabi M, Deporter D. The effects of laser microgrooves on hard and soft tissue attachment to implant collar surfaces: a literature review and interpretation. Int J Periodontics Restorative Dent 2013; 33(6): e145-52.

[http://dx.doi.org/10.11607/prd.1629] [PMID: 24116369]

[22] JAMA 2001; 285: 785-95.

[http://dx.doi.org/10.1001/jama.285.6.785] [PMID: 11176917]

[23] Reddy TK, Kumaravel N. Bone density assessment of oral implant sites using texture parameters. Int J Image Data Fusion 2011; 2: 167-80.

[http://dx.doi.org/10.1080/19479832.2010.518572]

[24] Pauwels R, Nackaerts O, Bellaiche N, et al. Variability of dental cone beam CT grey values for density estimations. Br J Radiol 2013;
86(1021)20120135

[http://dx.doi.org/10.1259/bjr.20120135] [PMID: 23255537]

[25] Haralick RM, Shanmugan K, Dinstein I. Textural features for image classification. IEEE Trans Inf Technol Biomed 1973; 3: 610-21.

[26] Ogiso M, Tabata T, Kuo PT, Borgese D. A histologic comparison of the functional loading capacity of an occluded dense apatite implant and the natural dentition. J Prosthet Dent 1994; 71(6): 581-8. [http://dx.doi.org/10.1016/0022-3913(94)90441-3] [PMID: 8040820]

[27] Heitz-Mayfield LJ, Schmid B, Weigel C, et al. Does excessive occlusal load affect osseointegration? An experimental study in the dog. Clin Oral Implants Res 2004; 15(3): 259-68.

[http://dx.doi.org/10.1111/j.1600-0501.2004.01019.x] [PMID: 15142087]

[28] Berglundh T, Abrahamsson I, Lindhe J. Bone reactions to longstanding functional load at implants: an experimental study in dogs. J Clin Periodontol 2005; 32(9): 925-32.

[http://dx.doi.org/10.1111/j.1600-051X.2005.00747.x]

[PMID: 16104954]

[29] Piattelli A, Corigliano M, Scarano A, Costigliola G, Paolantonio M. Immediate loading of titanium plasma-sprayed implants: an histologic analysis in monkeys. J Periodontol 1998; 69(3): 321-7. [http://dx.doi.org/10.1902/jop.1998.69.3.321] [PMID: 9579618]

[30] Gotfredsen K, Berglundh T, Lindhe J. Bone reactions adjacent to titanium implants subjected to static load. A study in the dog (I). Clin Oral Implants Res 2001; 12(1): 1-8.

[http://dx.doi.org/10.1034/j.1600-0501.2001.012001001.x] [PMID: 11168265]

[31] Roberts WE, Smith RK, Zilberman Y, Mozsary PG, Smith RS. Osseous adaptation to continuous loading of rigid endosseous implants. Am J Orthod 1984; 86(2): 95-111. [http://dx.doi.org/10.1016/0002-9416(84)90301-4] [PMID: 6589962]

[32] Carneiro LS, da Cunha HA, Leles CR, Mendonça EF. Digital subtraction radiography evaluation of longitudinal bone density changes around immediate loading implants: a pilot study. Dentomaxillofac Radiol 2012; 41(3): 241-7.

[http://dx.doi.org/10.1259/dmfr/89401091] [PMID: 22074866]

[33] Mundim MBV, Dias DR, Costa RM, Leles CR, Azevedo-Marques PM, Ribeiro-Rotta RF. Intraoral radiographs texture analysis for dental implant planning. Comput Methods Programs Biomed 2016; 136: 89-96.

[http://dx.doi.org/10.1016/j.cmpb.2016.08.012] [PMID: 27686706]

[34] Appleton RS, Nummikoski PV, Pigno MA, Cronin RJ, Chung KH. A radiographic assessment of progressive loading on bone around single osseointegrated implants in the posterior maxilla. Clin Oral Implants Res 2005; 16(2): 161-7.

[http://dx.doi.org/10.1111/j.1600-0501.2004.01089.x]

[PMID: 15777325]

[35] Buckland-Wright JC, Lynch JA, Rymer J, Fogelman I. Fractal signature analysis of macroradiographs measures trabecular organization in lumbar vertebrae of postmenopausal women. Calcif Tissue Int 1994; 54(2): 106-12.

[http://dx.doi.org/10.1007/BF00296060] [PMID: 8012865]

[36] Fazzalari NL, Parkinson IH. Fractal properties of cancellous bone of the iliac crest in vertebral crush fracture. Bone 1998; 23(1): 53-7. [http://dx.doi.org/10.1016/S8756-3282(98)00063-5] [PMID: 9662130]

[37] Jolley L, Majumdar S, Kapila S. Technical factors in fractal analysis of periapical radiographs. Dentomaxillofac Radiol 2006; 35(6): 393-7. [http://dx.doi.org/10.1259/dmfr/30969642] [PMID: 17082328]

[38] Chen B, Wu W, Sun W, Zhang Q, Yan F, Xiao Y. RANKL expression in periodontal disease: where does RANKL come from? BioMed Res Int 2014; 2014731039

[http://dx.doi.org/10.1155/2014/731039] [PMID: 24719884]

[39] Zaidi M. Skeletal remodeling in health and disease. Nat Med 2007; 13(7): 791-801.

[http://dx.doi.org/10.1038/nm1593] [PMID: 17618270]

[40] Kadkhodazadeh M, Ebadian AR, Gholami GA, Khosravi A, Tabari ZA. Analysis of RANKL gene polymorphism (rs9533156 and rs2277438) in Iranian patients with chronic periodontitis and periimplantitis. Arch Oral Biol 2013; 58(5): 530-6.

[http://dx.doi.org/10.1016/j.archoralbio.2012.10.015]

[PMID: 23177932]

[41] Akoğlan M, Tatli U, Kurtoğlu C, Salimov F, Kürkçü M. Effects of different loading protocols on the secondary stability and peri-implant bone density of the single implants in the posterior maxilla. Clin Implant Dent Relat Res 2017; 19(4): 624-31.

[http://dx.doi.org/10.1111/cid.12492] [PMID: 28493347]

[42] Ghoveizi R, Alikhasi M, Siadat MR, Siadat H, Sorouri M. A 
radiographic comparison of progressive and conventional loading on crestal bone loss and density in single dental implants: a randomized controlled trial study. J Dent (Tehran) 2013; 10(2): 155-63.

[PMID: 23724215]

[43] Albrektsson T, Zarb G, Worthington P, Eriksson AR. The long-term efficacy of currently used dental implants: a review and proposed criteria of success. Int J Oral Maxillofac Implants 1986; 1(1): 11-25. [PMID: 3527955]

[44] Nevins M, Kim DM, Jun S-H, Guze K, Schupbach P, Nevins ML. Histologic evidence of a connective tissue attachment to laser microgrooved abutments: a canine study. Int $\mathrm{J}$ Periodontics Restorative Dent 2010; 30(3): 245-55.

[PMID: 20386781]

[45] Nevins M, Nevins ML, Camelo M, Boyesen JL, Kim DM. Human histologic evidence of a connective tissue attachment to a dental implant. Int J Periodontics Restorative Dent 2008; 28(2): 111-21. [PMID: 18546807]

[46] Listgarten MA. Soft and hard tissue response to endosseous dental implants. Anat Rec 1996; 245(2): 410-25.

[http://dx.doi.org/10.1002/(SICI)1097-0185(199606)245:2<410::AIDAR20>3.0.CO;2-R] [PMID: 8769676]

[47] Kim S, Oh KC, Han DH, et al. Influence of transmucosal designs of three one-piece implant systems on early tissue responses: a histometric study in beagle dogs. Int J Oral Maxillofac Implants 2010; 25(2): 309-14.

[PMID: 20369089]

[48] Leong A, De Kok I, Mendonça D, Cooper LF. Molecular Assessment of Human Peri-implant Mucosal Healing at Laser-Modified and Machined Titanium Abutments. Int J Oral Maxillofac Implants 2018; 33(4): 895-904.

[http://dx.doi.org/10.11607/jomi.6367] [PMID: 30025007]

(C) 2020 Guarnieri et al.

This is an open access article distributed under the terms of the Creative Commons Attribution 4.0 International Public License (CC-BY 4.0), a copy of which is available at: (https://creativecommons.org/licenses/by/4.0/legalcode). This license permits unrestricted use, distribution, and reproduction in any medium, provided the original author and source are credited. 